\title{
Light-emitting diode-based indirect fluorescence detection for simultaneous determination of anions and cations in capillary electrophoresis
}

\author{
Shih-Ju Chen ${ }^{\mathrm{a}}$, Min-Jane Chen ${ }^{\mathrm{b}}$, Huan-Tsung Chang ${ }^{\mathrm{a}, *}$ \\ a Department of Chemistry, National Taiwan University, Roosevelt Road, Section 4, Taipei 106, Taiwan \\ $\mathrm{b}$ Department of Applied Chemistry, National Chaiyi University, Chaiyi, Taiwan
}

Received 15 May 2003; received in revised form 17 July 2003; accepted 8 August 2003

\begin{abstract}
This report presents simultaneous analysis of cations and anions by capillary electrophoresis (CE) in conjunction with indirect fluorescence detection using a blue light-emitting diode (LED), based on the displacement of fluorescein with anionic EDTA-metal complexes and anions. A new focusing system combined with a plastic lens and a $40 \times$ objective was developed and used effectively to focus the diverging beam of the LED on the capillary. The optimum compositions for simultaneous analysis of metal ions and anions are the samples prepared in $5 \mathrm{mM}$ borate, $\mathrm{pH} 9.2$, containing $2 \mathrm{mM}$ EDTA and the background electrolytes (BGEs) consisting of $5 \mathrm{mM}$ borate buffer, $5 \mu \mathrm{M}$ fluorescein, and $1 \mu \mathrm{M} \mathrm{NaCl}$ at $\mathrm{pH} 9.2$. Using this pre-capillary complexation method, the analysis of a sample containing five metal ions and eight anions was accomplished in $8 \mathrm{~min}$, with the relative standard deviation values for the migration times less than $2.0 \%$. The peak heights against the concentrations of the metal ions and anions are linear in 10-1000 and 50-2000 $\mu \mathrm{M}$, with correlation coefficients better than 0.998 , and 0.982 , respectively. The limits of detection at a signal-to-noise ratio 3 of up to $14.6 \mu \mathrm{M}$ for formate and as low as $3.7 \mu \mathrm{M}$ for $\mathrm{Ni}^{2+}$. The results of the analyses of pond water and a Chinese herbal soup present the advantages of this method, including simplicity, rapidity, reproducibility, and low costs. (c) 2003 Elsevier B.V. All rights reserved.
\end{abstract}

Keywords: Light-emitting diode; Fluorescence detection; Detection, electrophoresis; Indirect detection; Fluorescein

\section{Introduction}

Capillary electrophoresis (CE) is a powerful separation technique for a wide number of small solutes [1-10] and has been recognized as a technique complementary to ion chromatography because it provides the advantages of rapidity, high efficiency,

\footnotetext{
* Corresponding author. Tel.: +886-2-23621963; fax: +886-2-23621963.

E-mail address: changht@ntu.edu.tw (H.-T. Chang).
}

sensitivity, as well as minute amounts of samples and reagents required. The merit of $\mathrm{CE}$ is also shown in simultaneous analysis of cations and anions by two-end injection techniques [11] or by adding complexing agents (to form metal-chelates) such as 4-(2pyridylazo)-resorcinol [12], 2,6-pyridinedicarbozylic acid [13], 18-crown-6 [14,15] to the background electrolytes (BGEs).

A number of $C E$ techniques based on indirect absorption $[1,13,16]$ and indirect laser-induced fluorescence (ILIF) $[17,18]$ have been developed for analyses 
of solutes that lack a suitable chromophore and fluorophore, respectively. Stable and high-power lasers such as argon ion laser have been used for the analyses of ionic solutes with good sensitivity $[17,18]$. Alternatively, low costly light sources such as light-emitting diodes (LEDs), diode lasers, and He-Ne lasers have gained attraction in CE [19-24]. LEDs provide the advantages of a long life, high intensities at a variety of wavelengths (ranging from blue to red), comparable stability with that of conventional light source such as Xe lamps, small sizes, and ease of operation. Unlike LEDs that possess spectra bandwidth from 20 to $100 \mathrm{~nm}$, the output of diode lasers is quite monochromatic $(<10 \mathrm{~nm})$. It is also reported that the baseline stability achieved by using a violet diode laser was better than that using a He-Cd laser [23].

To achieve better sensitivity, the indirect system should provide a high dynamic reserve (DR), according to Eq. (1) [25]:

$C_{\mathrm{LOD}}=\frac{C_{\mathrm{m}}}{\mathrm{DR} \times \mathrm{TR}}$

where $C_{\mathrm{LOD}}$ is the concentration limit of detection, and $C_{\mathrm{m}}$ the concentration of the fluorophore in the mobile phase, DR the ability to measure a small change on top of a large signal, and equals to a signal-to-noise ratio $(\mathrm{S} / \mathrm{N})$ of the background signal, and $\mathrm{TR}$ refers to the transfer ratio, which is the degree of displacement of the probe (co-ion) by the analyte. In view of signal, it is extremely important to select a fluorophore that has a high molar absorption coefficient and high quantum efficiency. On the other hand, a low background noise can be achieved with a stable probe and a stable laser. A high TR is also required for optimum sensitivity as shown in Eq. (1). This can be realized when the mobility of a highly charged fluorophore is comparable to that of the analytes [26-28]. Such a characteristic is also important with respect to resolution since the peak profile for the analyte with its mobility similar to the probe is generally symmetric and sharp. Finally, it is essential that the mobility of the buffer-ions should be as different from that of analytes as possible for achieving reproducibility and high sensitivity $[27,29,30]$.

A number of fluorophores have been tested for the analyses of solutes by CE-ILIF [22-24]. Among these, fluorescein is one of the most common dyes added to the BGEs for the analyses of anions such as fatty acids, phenolic acids, and inorganic acids, simply because it is highly fluorescent at $520 \mathrm{~nm}$ when excited at $488 \mathrm{~nm}$ by an argon ion laser, stable, water soluble, and low costly [31-33]. One common point in those studies is that negative signals stem from the displacement of fluorescein in the BGE by the analytes (co-ions). The analysis of cationic ions such as alkali and alkaline earth metal ions using fluorescein represents another feature of ILIF [34]. In contrary, positive peaks were observed because changes in the counterion concentration as a result of greater mobilities of the analytes than that of the co-ion [35]. Although this method is not as sensitive as that using cationic fluorophores such as quinine sulfate [36] and $\mathrm{Ce}^{3+}$ ions [37], it is less costly because a relatively expensive $\mathrm{Ar}^{+}$laser at $360 \mathrm{~nm}$ used in the later.

In this report our main aim is toward the simultaneous analysis of cationic and anionic solutes by CE using fluorescein as the probe and an LED with a maximum output at $460 \mathrm{~nm}$ as the light source. Please note that hereafter we use ILEDIF to represent indirect LED-induced fluorescence. In this study, the negative signals stem simply from the displacement of fluorescein with anions as well as with the anionic complexes formed between metal ions and EDTA. Owing to the $\mathrm{pH}$ dependence of the fluorescence intensity of fluorescein and the stability of the EDTA complexes, our particular attention has been paid to exploring the $\mathrm{pH}$ effect on resolution and sensitivity for the metal ions.

\section{Experimental}

\subsection{Chemicals}

All chemicals were of reagent grade and were obtained from Sigma (St. Louis, MO, USA). The $\mathrm{pH}$ values of $5 \mathrm{mM}$ borate buffer containing $5 \mu \mathrm{M}$ fluorescein with/without $\mathrm{NaCl}$ were adjusted with $\mathrm{NaOH}$ to certain $\mathrm{pH}$ values. The analytes were prepared in $5 \mathrm{mM}$ borate buffers containing $2 \mathrm{mM}$ EDTA at $\mathrm{pH}$ values ranging from 9.2 to 10.0 . To minimize matrix interference, $10 \mu \mathrm{l}$ water sample from a pond in the campus or the sample of a Chinese herbal soup "Si Wu Tang" was mixed with an aliquot of $90 \mu 15 \mathrm{mM}$ borate buffer containing $10 \mathrm{mM}$ EDTA, pH 9.2. It is noted that using $10 \mathrm{mM}$ EDTA is to guarantee quantitative results. 


\subsection{CE system}

The basic design of the CE-ILEDIF system has been previously described [18]. Briefly, a high-voltage power supply (Gamma High Voltage Research Inc., Ormond Beach, FL, USA) was used to drive electrophoresis. The entire detection system was housed in a black box with a high-voltage interlock. The high-voltage end of the separation system was put in a laboratory-made plexiglass box for safety. An LED with a maximum output at $460 \mathrm{~nm}$ in the range of 430-510 nm (Ledtech, Taipei, Taiwan) was obtained from a local electronic store and used for excitation. A laboratory-made power supply with adjusted voltages up to $5 \mathrm{~V}$ was used to drive the LED. In this study, the applied voltage was set at $4 \mathrm{~V}$. As shown in Fig. 1, the excitation light was focused on the capillary with a plastic lens (Raise Electro-Optics, Taipei, Taiwan) and a $40 \times$ objective (numerical aperture $=0.25$ ). The fluorescence was collected with a $10 \times$ objective (numerical aperture $=0.25$ ). One OG 570 cut-off filter was used to block scattered lights before the emitted light reached the photomultiplier tube (R928, Hamamatsu Photonics K.K., Shizuoka-Ken, Japan). The fluorescence signal was directly transferred through a $10 \mathrm{k} \Omega$ resistor to a 24-bit A/D interface at $10 \mathrm{~Hz}$ (Borwin, JMBS Developments, Le Fontanil, France) and stored in a personal computer. Fused-silica capillaries (Polymicro Technologies, Phoenix, AZ, USA) were $40 \mathrm{~cm}(30 \mathrm{~cm}$ in effective length $) \times 75 \mu \mathrm{m}$ i.d.

\subsection{Electrophoretic procedures}

New capillaries were rinsed with $0.5 \mathrm{M} \mathrm{NaOH}$ overnight. Prior to analysis, the capillary was flushed with the running buffer for $20 \mathrm{~s}$, and was subsequently conditioned with the running buffers for $20 \mathrm{~min}$ at $15 \mathrm{kV}$. To obtain a relatively stable baseline, it is suggested that the capillary was conditioned with the running buffers for $5 \mathrm{~min}$ at $15 \mathrm{kV}$ after each run. Hydrodynamic injection was conducted at $13 \mathrm{~cm}$ height for $2 \mathrm{~s}$.

\section{Results and discussion}

\subsection{Effect of pH and EDTA concentration on sensitivity and resolution}

With respect to sensitivity, the concentration of fluorescein in the BGE should be carefully investigated according to Eq. (1). Investigating the concentration range of $0.1 \mu \mathrm{M}$ to $0.1 \mathrm{mM}$, we have suggested that a suitable fluorescein concentration is $5 \mu \mathrm{M}$ (DR is

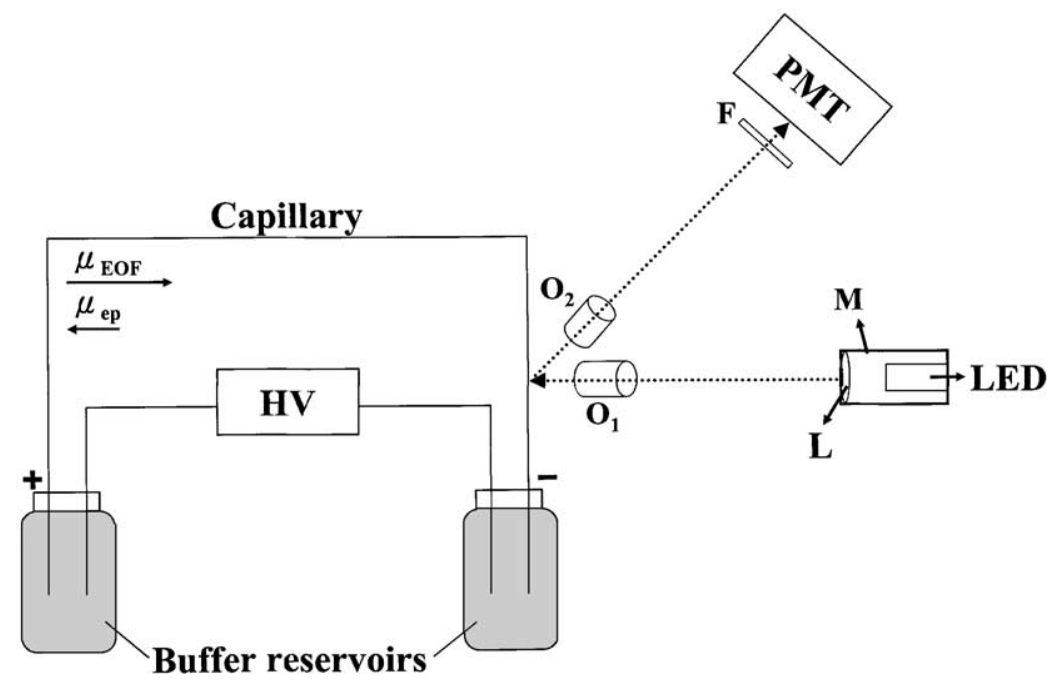

Fig. 1. Schematic of the CE-ILEDIF. HV: high-voltage power supply; F: cut-off filter; L: plastic lens; M: metallic tube (7 mm i.d., exist slit i.d. $2 \mathrm{~mm}$ ); $\mathrm{O}_{1}: 40 \times$ objective; $\mathrm{O}_{2}: 10 \times$ objective; $\mu_{\mathrm{EOF}}$ : EOF mobility; $\mu_{\mathrm{ep}}$ : electrophoretic mobility for anionic EDTA-metal complexes and anions. 
greater than 350). To ensure good sensitivity and resolution, the samples were prepared in borate solutions containing EDTA. The peak height for $\mathrm{Ca}^{2+}$ at $50 \mu \mathrm{M}$ increased about four times when the EDTA concentration was increased from $50 \mu \mathrm{M}$ to $2 \mathrm{mM}$ in the sample. The sensitivity was about the same when increasing EDTA concentration from 2 to $20 \mathrm{mM}$, slight loss of resolution between $\mathrm{Mg}^{2+}$ and $\mathrm{Ca}^{2+}$ occurred. When adding EDTA to the BGE, the metal ions form anionic EDTA-metal complexes to a great extent, but leading to loss of resolution. In addition, smaller TR values are problematic, mainly due to competitive displacement of EDTA and fluorescein by the anionic complexes and other anionic analytes. Thus EDTA was not added to the BGE in this study.

The role of $\mathrm{pH}$ playing is important in determining sensitivity and resolution because it affects the fluorescence intensity of fluorescein, the stability of the anionic EDTA-metal complexes, the electroosmotic flow (EOF) mobility, and the electrophoretic mobilities of the analytes. The fluorescence intensity of fluorescein monotonically increases from $\mathrm{pH} 4.0$ to 9.0 and reaches plateau above $\mathrm{pH} 9.0$ [28]. To minimize the shift in the baseline while achieving a high DR, the analysis conducted at $\mathrm{pH}>9.0$ is preferred. In view of the formation of complexes between metal ions and EDTA $\left(\mathrm{Y}^{4-}\right)$, it is also preferable to conduct the separation at high $\mathrm{pH}$. However, attention must be paid to prevent the formation of metal-hydroxide (or oxide) precipitates at high $\mathrm{pH}$ [38]. In addition, the competitive displacement of fluorescein between EDTA-metal complexes and hydroxide ions at higher $\mathrm{pH}(>10.0)$ is problematic. Thus, the $\mathrm{pH}$ effect was explored in the range of 9.2-10.0 at a constant EDTA concentration of $2 \mathrm{mM}$ and a constant fluorescein concentration of $5 \mu \mathrm{M}$.
Table 1 shows that the negative peak heights for $\mathrm{Ca}^{2+}, \mathrm{Mg}^{2+}$, and $\mathrm{Ni}^{2+}$ decrease with increasing $\mathrm{pH}$ from 9.2 to 10.0 although more $\mathrm{Y}^{4-}$ formed. Another interesting result is that the electrophoretic mobility values for the three metal ions decrease with increasing $\mathrm{pH}$, which is in agreement with a reported result [34]. The impact of ionic strength on the change in the electrophoretic mobility is negligible since only slight changes in the EOF (the mobilities were 9.01 and $9.03 \times 10^{-4} \mathrm{~cm}^{2} \mathrm{~V}^{-1} \mathrm{~s}^{-1}$ at $\mathrm{pH} 9.2$ and 10.0 , respectively). The fact of fairly constant peak heights and electrophoretic mobility values for citrate $\left(\mathrm{p} K_{1}, \mathrm{p} K_{2}\right.$, and $\mathrm{p} K_{3}$ are $3.13,4.76$, and 5.40, respectively) at different $\mathrm{pH}$ supports our suggestion. Thus, we inferred that hydroxide ions deteriorated the system sensitivity more significantly at $\mathrm{pH}$ values higher than 9.2.

\subsection{Optimum detection system}

Although LEDs are very cheap and low-noise light sources, there are some shortages when compared to lasers. Their emission profiles are relatively broad. For example, the emission profile of the blue LED used in this study spans from 430 to $510 \mathrm{~nm}$, with a maximum emission at $460 \mathrm{~nm}$. It is also more difficult to focus the diverging beam of an LED. As a result, the system using an LED is not as sensitive as that using any laser under the same experimental conditions. To improve sensitivity, several attempts have been made when using LEDs, including so-called pigtailling approach [20], the use of iris and lens [39], miniaturized liquid-core waveguide [40], and a time-discrimination and average acquisition system [41]. Some of these systems have provided LODs down to the order of $\mu \mathrm{M}$ to sub- $\mu \mathrm{M}$. Herein, we tested a new focusing system combined with a plastic lens and an objective, which

Table 1

Effect of $\mathrm{pH}$ on mobility and peak height for the analytes

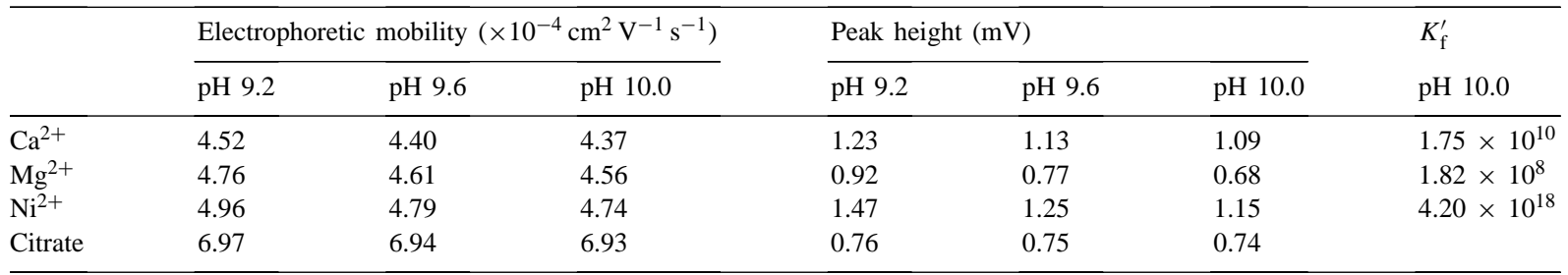

Buffer electrolytes were composed of $5 \mathrm{mM}$ borate and $5 \mu \mathrm{M}$ fluorescein. Electrophoretic mobility $\left(\mu_{\mathrm{ep}}\right)$ is positive for anions migrating toward anode against $\mathrm{EOF}\left(\mu_{\mathrm{EOF}}>\mu_{\mathrm{ep}}\right)$ in this study. 


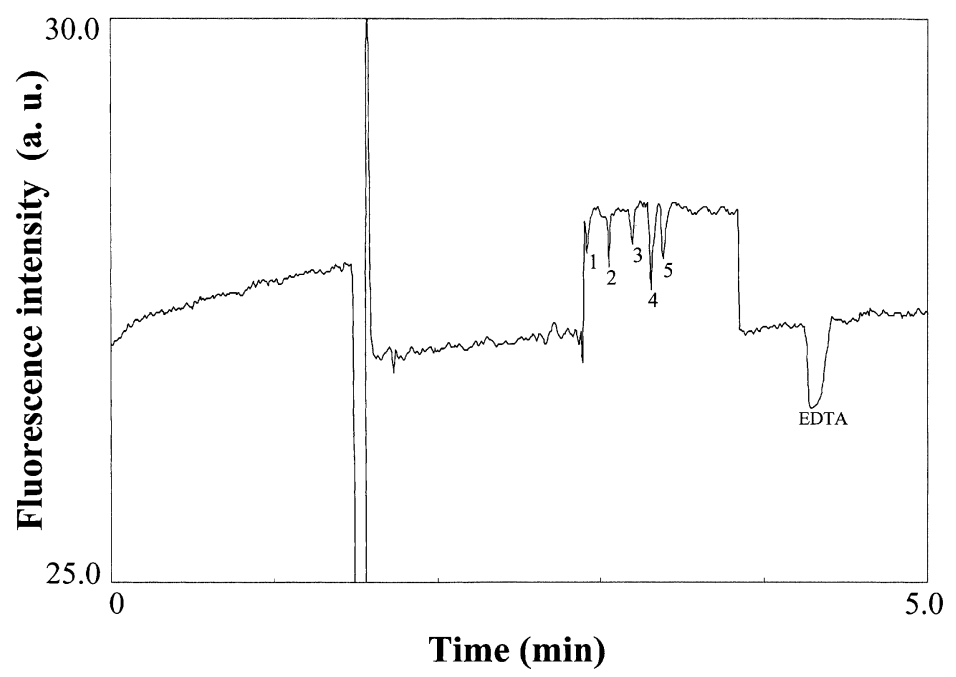

Fig. 2. Electropherogram of five EDTA-metal complexes at $15 \mathrm{kV}$. Peak identities: (1) $\mathrm{Ba}^{2+}$; (2) $\mathrm{Ca}^{2+}$; (3) $\mathrm{Mg}^{2+}$; (4) $\mathrm{Ni}^{2+}$; (5) $\mathrm{Cu}^{2+}$. Capillary: $40 \mathrm{~cm}(30 \mathrm{~cm}$ in effective length) $\times 75 \mu \mathrm{m}$ i.d.; filled with $5 \mathrm{mM}$ borate buffer containing $5 \mu \mathrm{M}$ fluorescein, pH 9.2 . The analytes at the concentration of $50 \mu \mathrm{M}$ were prepared in $5 \mathrm{mM}$ borate buffer containing $2 \mathrm{mM}$ EDTA, pH 9.2. Hydrodynamic injection was conducted at $13 \mathrm{~cm}$ height for $2 \mathrm{~s}$.

allows one to easily focus the light onto the capillary and to minimize the noise from scattering. The diverging light from the LED was confined with a narrow metal tube (i.d. $7 \mathrm{~mm}$ and exit slit i.d. $2 \mathrm{~mm}$ ) and focused with the plastic lens before entering a $40 \times$ objective. The light was then focused on the capillary with the objective. With such a simple system, we obtained a DR value of 405 when using the BGE containing $5 \mu \mathrm{M}$ fluorescein, $\mathrm{pH}$ 9.2. As a result, on the basis of the peak heights, the limits of detection (LODs) at a $\mathrm{S} / \mathrm{N}=3$ are 5.5 and $3.7 \mu \mathrm{M}$ for $\mathrm{Ca}^{2+}$ and $\mathrm{Ni}^{2+}$, respectively.

Fig. 2 presents that the separation of five metal ions was accomplished in $4 \mathrm{~min}$, showing step changes in the baseline with the R.S.D. values for the shift times less than $1.8 \%$. The magnitude of the step change occurring immediately after the EOF (1.72 $\mathrm{min})$ depends strongly on the concentration of borate (co-ion) in the BGE when other BGE and the sample compositions are kept the same. The other step change occurs at $2.76 \mathrm{~min}$ and is related to fluorescein concentration when the sample and other BGE compositions are kept the same. At fluorescein concentration $>10 \mu \mathrm{M}$, the peaks corresponding to the EDTA-metal complexes and EDTA were in the same baseline level (no shift at $4.00 \mathrm{~min}$ ). At $1 \mu \mathrm{M}$ fluorescein, the step change (the baseline between 2.72 and $4.00 \mathrm{~min}$ is lower than those before $2.72 \mathrm{~min}$ and after $4.00 \mathrm{~min}$ ) is contrary to that shown in Fig. 2. It is interesting to point out that the peaks for the anionic EDTA-metal complexes appear between 2.85 and $3.60 \mathrm{~min}$, which are between the peaks for fluorescein $(2.77 \mathrm{~min})$ and for EDTA (4.23 min). At $\mathrm{pH}$ 9.2, the main species of EDTA is $\mathrm{HY}^{3-}$, thus we infer that the anionic EDTA-metal complexes are the main species in the course of the separation. This conclusion is also supported by the fact of negative peak profiles shown in the electropherogram. Thus the detection of the metal ions is based on the displacement of fluorescein by the anionic EDTA-metal complexes. As a result, the LODs are at the $\mu \mathrm{M}$ level, which are much lower than those (sub mM) for $\mathrm{Na}^{+}$and $\mathrm{K}^{+}$(positive signals). The electropherogram in Fig. 2 shows a trend that the migration time is longer for a metal ion forming stable complexes with EDTA. For example, the migration time for $\mathrm{Ni}^{2+}$ is longer than that for $\mathrm{Ba}^{2+}$.

\subsection{Simultaneous analysis of cations and anions}

Next, we tested the separation of cations and anions using fluorescein as the probe. The electropherogram A in Fig. 3 presents the separation of five cations 


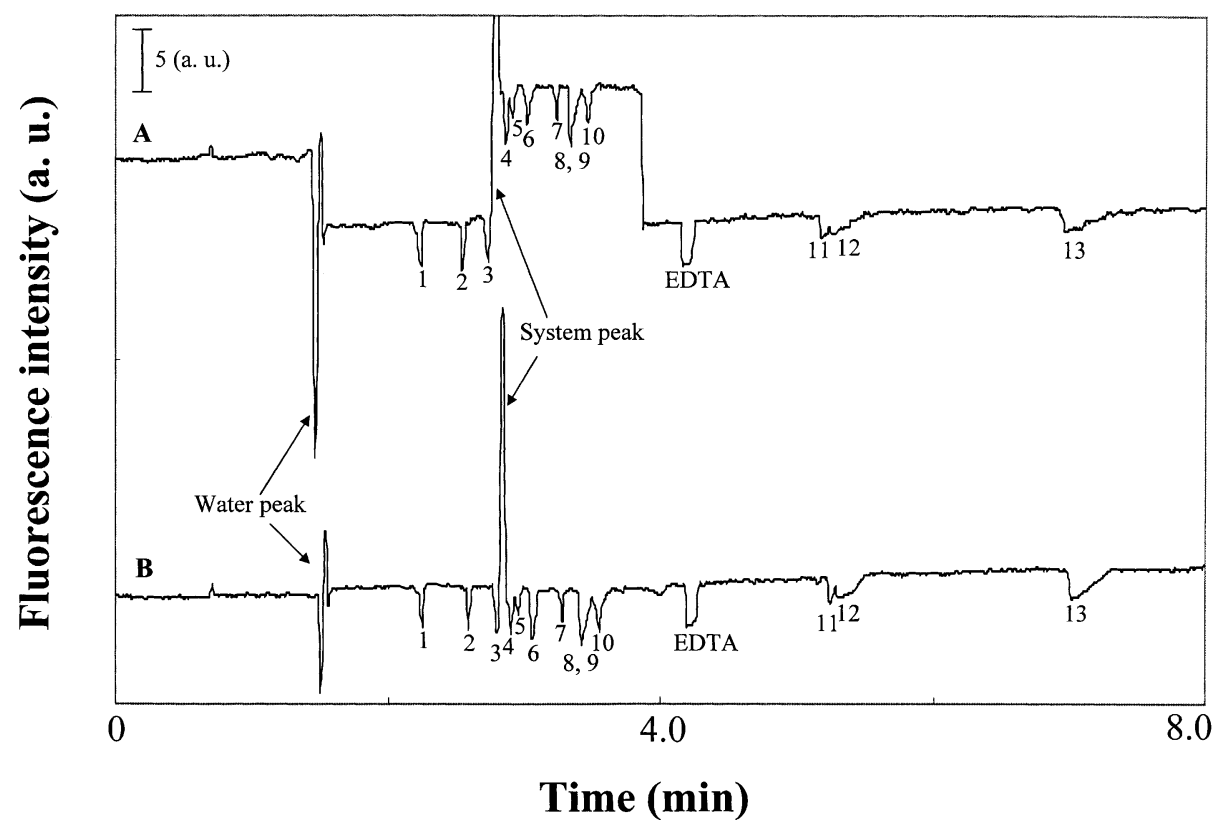

Fig. 3. Electropherograms of five cations and eight anions in the absence (A) and presence (B) of $1 \mu \mathrm{M} \mathrm{NaCl}$. Peak identities: (1) lactate; (2) butyrate; (3) salicylate; (4) propionate; (5) $\mathrm{Ba}^{2+}$; (6) $\mathrm{Ca}^{2+}$; (7) $\mathrm{Mg}^{2+}$; (8) $\mathrm{Ni}^{2+}$; (9) acetate; (10) $\mathrm{Cu}^{2+}$; (11) phosphate; (12) formate; (13) citrate. The sample containing cationic analytes at the concentrations of $50 \mu \mathrm{M}$ and the anionic analytes at the concentrations of $100 \mu \mathrm{M}$ was prepared in $5 \mathrm{mM}$ borate buffer containing $2 \mathrm{mM}$ EDTA, pH 9.2. Other conditions were as the same in Fig. 2.

and eight anions prepared in $5 \mathrm{mM}$ borate buffer containing $2 \mathrm{mM}$ EDTA, pH 9.2, using a capillary filled with $5 \mathrm{mM}$ borate buffer containing $5 \mu \mathrm{M}$ fluorescein, $\mathrm{pH}$ 9.2. It is interesting to note that the peaks corresponding to EDTA-metal complexes appear between monoprotic organic acids (except small organic acids such as acetate and formate) and polyprotic acids. The result clearly shows that addition of cationic and anionic probes to the BGE is no longer needed for the simultaneous determination of cationic and anionic solutes $[17,42]$, preventing problems of finding two fluorophores with similar optical properties (excitation and emission wavelengths) as well as chemical and physical properties (solubility and stability). Compared to the peaks for the EDTA-metal complexes and the weak acids (salicylate, propionate, acetate), those for phosphate, formate, and citrate are relatively broad, mainly because of greater differential mobilities relative to the probe (fluorescein).

Next, we investigated the effect of $\mathrm{NaCl}$ in the BGE on simultaneous separation of cations and anions. The baseline shift decreased with increasing $\mathrm{NaCl}$ concen- tration up to $1 \mu \mathrm{M}$. In the $\mathrm{NaCl}$ concentration range of 1-10 $\mu \mathrm{M}$, the baseline shift did not occur. However, with increasing $\mathrm{NaCl}$ concentration, increases in the baseline noise, slight decreases in the fluorescence, and decreases in TR were found, leading to poor sensitivity. Fig. 3 shows differential electropherograms when conducting the separations of the same sample in the absence (A) and presence (B) of $1 \mu \mathrm{M} \mathrm{NaCl}$ in the BGE. The electropherogram B (Fig. 3) shows no shift in the baseline and narrower peak profiles for the polyprotic acids in the presence of $1 \mu \mathrm{M} \mathrm{NaCl}$. Since there were already $10 \mathrm{mM} \mathrm{Na}^{+}$(from borax) in the BGE, such dramatic changes should be related to $\mathrm{Cl}^{-}$ (electrophoretic mobility: $7.92 \times 10^{-4} \mathrm{~cm}^{2} \mathrm{~V}^{-1} \mathrm{~s}^{-1}$ ). It is noted that the reproducibility and sensitivity improved in the presence of salt. For example, the R.S.D. values of the peak heights for the last three peaks decreased from 6.0 to $4.0 \%$ in the presence of salt. Table 2 shows the LOD values for the analytes are between 3.0 and $15.0 \mu \mathrm{M}$, which are about 1.5-4 times lower than that in the absence of salt. Please note that the LODs for the comigrating analytes $\left(\mathrm{Ni}^{2+}\right.$ and 
Table 2

Migration time, reproducibility, mobility, and LOD for five cations and eight anions

\begin{tabular}{|c|c|c|c|c|c|c|c|c|c|c|c|c|c|}
\hline & Lactate & Butyrate & Salicylate & Propionate & $\mathrm{Ba}^{2+}$ & $\mathrm{Ca}^{2+}$ & $\mathrm{Mg}^{2+}$ & $\mathrm{Ni}^{2+}$ & Acetate & $\mathrm{Cu}^{2+}$ & Phosphate & Formate & Citrate \\
\hline$t_{\mathrm{m}}(\min )$ & 2.25 & 2.59 & 2.80 & 2.91 & 2.96 & 3.07 & 3.28 & 3.36 & 3.38 & 3.55 & 5.24 & 5.31 & 7.01 \\
\hline R.S.D. ${ }^{\mathrm{a}}(\%)$ & 0.46 & 0.41 & 0.63 & 0.31 & 0.45 & 0.44 & 0.66 & 0.45 & 0.44 & 0.39 & 1.27 & 1.08 & 1.19 \\
\hline $\begin{array}{l}\mu_{\mathrm{ep}}\left(\times 10^{-4}\right. \\
\left.\mathrm{cm}^{2} \mathrm{~V}^{-1} \mathrm{~s}^{-1}\right)\end{array}$ & 2.94 & 3.72 & 4.10 & 4.29 & 4.36 & 4.53 & 4.80 & 4.90 & 4.93 & 5.12 & 6.33 & 6.37 & 6.98 \\
\hline $\operatorname{LOD}^{\mathrm{b}}(\mu \mathrm{M})$ & 13.7 & 12.1 & 14.5 & 4.7 & 11.9 & 5.5 & 8.3 & 3.7 & 4.7 & 6.6 & 12.8 & 14.6 & 7.6 \\
\hline
\end{tabular}

Conditions were as in Fig. 3B.

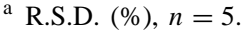

b $\mathrm{S} / \mathrm{N}=3$.

acetate) were obtained when only one of the paired ions was present. The EOF mobility slightly changed from 9.01 to $8.89 \times 10^{4} \mathrm{~cm}^{2} \mathrm{~V}^{-1} \mathrm{~s}^{-1}$ when the $\mathrm{NaCl}$ concentration was increased from 0 to $1 \mu \mathrm{M}$ and the R.S.D. values of the migration times for all of the analytes are less than $2.0 \%$ in both cases. Linearity between the peak height and the concentration of the metal ions was found in the range of $10-1000 \mu \mathrm{M}$, with $R^{2}>0.998$. Owing to a relatively broad peak profile, linearity for citrate is in the range of $50-2000 \mu \mathrm{M}$, with $R^{2}>0.982$.

\subsection{Analysis of pond water and Chinese herbal soup}

Fig. 4 shows the electropherogram of a water sample from a pond in the campus diluted 10 times with $5 \mathrm{mM}$ borate buffer, containing $10 \mathrm{mM}$ EDTA. We should point out that using $10 \mathrm{mM}$ EDTA (more than the total metal concentration interested in the sample) is necessary to provide quantitative results with only very slight loss of resolution. The four identified peaks correspond to $\mathrm{Ba}^{2+}, \mathrm{Ca}^{2+}, \mathrm{Mg}^{2+}$, and phosphate,

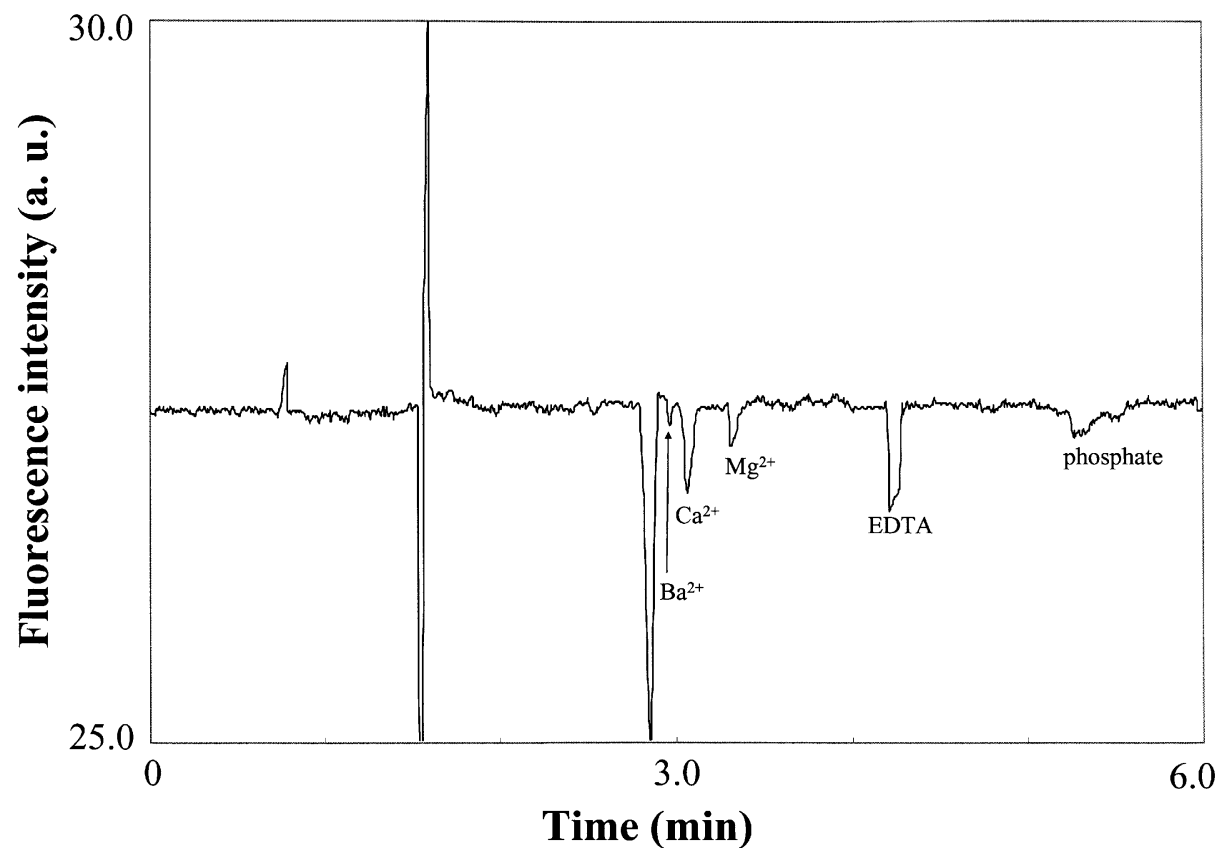

Fig. 4. Separation of pond water diluted 10 times with $5 \mathrm{mM}$ borate buffer containing $10 \mathrm{mM}$ EDTA, pH 9.2. Other conditions were as the same in Fig. 3B. 
Table 3

Analyses of pond water and Si Wu Tang

\begin{tabular}{|c|c|c|c|c|c|c|}
\hline Sample & Analyte & Migration time (min) & Slope $\left(\mathrm{mV} \mathrm{mM}^{-1}\right)$ & Intercept $(\mathrm{mV})$ & Correlation coefficient ${ }^{\mathrm{a}}$ & Concentration $(\mathrm{mM})^{\mathrm{b}}$ \\
\hline \multirow[t]{4}{*}{ Pond water } & $\mathrm{Ba}^{2+}$ & $2.97(1.12)$ & 7.230 & 0.17 & 0.995 & 0.27 \\
\hline & $\mathrm{Ca}^{2+}$ & $3.07(0.77)^{\mathrm{c}}$ & 8.395 & 0.603 & 0.998 & 0.72 \\
\hline & $\mathrm{Mg}^{2+}$ & $3.31(1.21)$ & 7.957 & 0.291 & 0.997 & 0.37 \\
\hline & Phosphate & $5.30(2.51)$ & - & - & - & - \\
\hline \multirow[t]{5}{*}{ Si Wu Tang } & Lactate & $2.23(0.82)$ & 2.251 & 0.402 & 0.976 & 1.79 \\
\hline & $\mathrm{Ca}^{2+}$ & $3.06(0.77)$ & 2.739 & 0.276 & 0.983 & 1.01 \\
\hline & $\mathrm{Mg}^{2+}$ & $3.24(1.21)$ & 2.777 & 0.268 & 0.987 & 0.97 \\
\hline & $\mathrm{Zn}^{2+}$ & $3.39(1.75)$ & 2.607 & 0.359 & 0.981 & 1.37 \\
\hline & Phosphate & $5.29(2.30)$ & - & - & - & - \\
\hline
\end{tabular}

The values in parentheses are in percent.

a Linear range: spiked analytes at the concentration from $10 \mu \mathrm{M}$ to $1 \mathrm{mM}$ and 0.1 to $1 \mathrm{mM}$ for pond water and for Si Wu Tang, respectively.

${ }^{\mathrm{b}}$ Conditions were as in Figs. 4 and 5.

c R.S.D. $(\%), n=8$.

respectively. A reproducible but broad peak corresponding to phosphate shows the quantitative disadvantage of this method. It is interesting to note that the system peak at $2.85 \mathrm{~min}$ is negative, which is different form those shown in Figs. 1 and 2. This is mainly due to the existence of other ionic solutes in the water sample. In order to determine the con- centrations of the metal ions, we spiked these three ions to the samples in the concentration range of $10 \mu \mathrm{M}-1 \mathrm{mM}$. Table 3 shows that the peak heights are proportional to the concentrations of $\mathrm{Ba}^{2+}, \mathrm{Ca}^{2+}$, and $\mathrm{Mg}^{2+}$ in the study range, with $R^{2}$ of $0.995,0.998$, and 0.997 , respectively. From the linear plots (not shown), we estimated the concentrations of $\mathrm{Ba}^{2+}$,

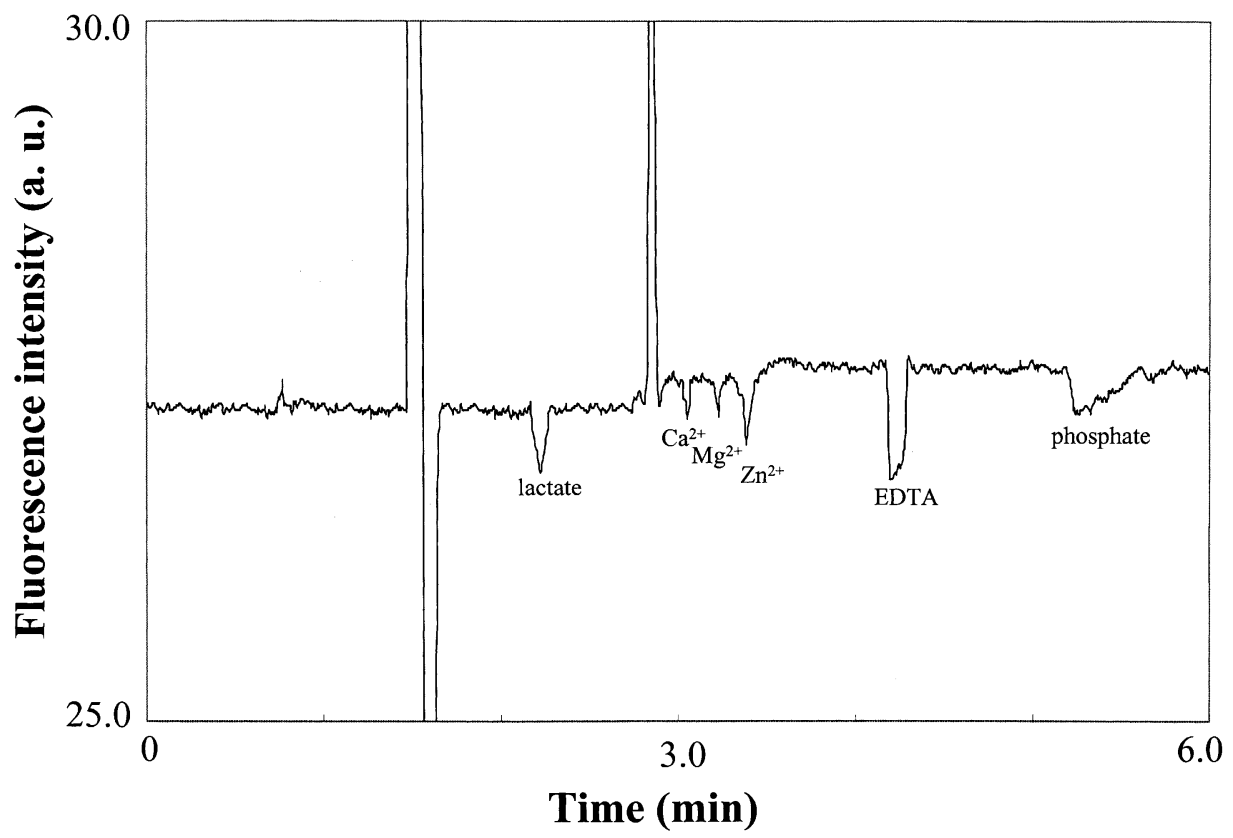

Fig. 5. Separation of Si Wu Tang diluted 10 times with $5 \mathrm{mM}$ borate buffer containing $10 \mathrm{mM}$ EDTA, pH 9.2. Other conditions were as the same in Fig. 3B. 
$\mathrm{Ca}^{2+}$ and $\mathrm{Mg}^{2+}$ in the pond water were $0.27,0.72$ and $0.37 \mathrm{mM}$, respectively.

The electropherograms in Fig. 5 presents the separation of a Chinese herbal soup "Si Wu Tang" diluted 10 times with $5 \mathrm{mM}$ borate containing $10 \mathrm{mM}$ EDTA, pH 9.2. To determine the concentrations of lactate, $\mathrm{Ca}^{2+}, \mathrm{Mg}^{2+}$, and $\mathrm{Zn}^{2+}$, the four ions in the concentration range of $0.1-1 \mathrm{mM}$ were spiked to the diluted samples. From the calibration plots, we estimated that the concentrations of lactate, $\mathrm{Ca}^{2+}, \mathrm{Mg}^{2+}$, and $\mathrm{Zn}^{2+}$ were $1.79,1.01,0.97$, and $1.37 \mathrm{mM}$, respectively. Such a high amount of $\mathrm{Zn}^{2+}$ in the soup is common in numerous Chinese herbals for nourishing kidney, mainly because it is believed that zinc plays a role in the immune system in the Chinese society [43]. Together with the results shown in Figs. 3 and 4, there is no doubt of the value of this method from a practical viewpoint.

\section{Conclusions}

We have progressed in developing a compact, low costly, and rapid system for the simultaneous determination of metal ions and anions by $\mathrm{CE}$ with indirect fluorescence detection. The new optical system allows ones to easily focus the diverging LED light to a $75 \mu \mathrm{m}$ capillary with minimized scattered and stray light. To optimize resolution and sensitivity, pre-capillary complexation method is suggested. The results shown in this study clearly present that the displacement of fluorescein with anionic EDTA-metal complexes provide appropriate sensitive, with the LODs between 3.7 and $11.9 \mu \mathrm{M}$ for the metal ions. In this study, we also demonstrated that adding a suitable amount of $\mathrm{NaCl}$ to the BGE is effective to improve the stability of the baseline. The utility of this method was proved in the analyses of metal ions, organic acids, and inorganic acids in a pond water sample and a Chinese herbal soup in $6.00 \mathrm{~min}$, with great reproducibility, speed, and good linearity.

\section{Acknowledgements}

This work was supported by the National Science Council of the Republic of China (NSC 91-2113-M-002-051).

\section{References}

[1] C. Johns, M. Macka, P.R. Haddad, Electrophoresis 24 (2003) 2150.

[2] C. Prata, P. Bonnafous, N. Fraysse, M. Treilhou, V. Poinsot, F. Couderc, Electrophoresis 22 (2001) 4129.

[3] Z. Chen, J. Wu, G.B. Baker, M. Parent, N.J. Dovichi, J. Chromatogr. A 914 (2001) 293.

[4] M. Molina, M. Silva, Electrophoresis 23 (2002) 2333.

[5] P. Britz-Mckibbin, S. Terabe, Chem. Record 2 (2002) 397.

[6] M.M. Hseih, C.E. Hsu, W.L. Tseng, H.T. Chang, Electrophoresis 23 (2002) 1633.

[7] W. Wall, J. Li, Z.E. Rassi, J. Sep. Sci. 25 (2002) 1231.

[8] A.R. Timerbaev, O.A. Shpigun, Electrophoresis 21 (2000) 4179.

[9] M. Muzikáŕ, J. Havel, M. Macka, Electrophoresis 23 (2002) 1796.

[10] A.R. Timerbaev, O.P. Semenova, O.M. Petrukhin, J. Chromatogr. A 943 (2002) 263.

[11] P. Kubáň, B. Karlberg, Anal. Chem. 70 (1998) 360.

[12] O.V. Krokhin, H. Hoshino, O.A. Shpigun, T. Yotsuyanagi, J. Chromatogr. A 776 (1997) 329.

[13] T. Soga, G.A. Ross, J. Chromatogr. A 834 (1999) 65.

[14] P. Kubáň, P. Kubáň, V. Kubáň, Electrophoresis 23 (2002) 3725.

[15] X. Xiong, S.F.Y. Li, J. Chromatogr. A 822 (1998) 125.

[16] I. Haumann, J. Boden, A. Mainka, U. Jegle, J. Chromatogr. A 895 (2000) 269.

[17] P. Zhang, G. Xu, J. Xiong, Y. Zheng, Q. Yang, F. Wei, J. Sep. Sci. 25 (2002) 155.

[18] Y.C. Chao, C.W. Whang, J. Chromatogr. A 663 (1994) 229.

[19] S.J. Williams, E.T. Bergstroem, D.M. Goodall, H. Kawazumi, K.P. Evans, J. Chromatogr. 636 (1993) 39.

[20] A.E. Bruno, F. Maystre, B. Krattiger, P. Nussbaum, E. Gassmann, Trends Anal. Chem. 13 (1994) 190.

[21] P.A.G. Butler, B. Mills, P.C. Hauser, Analyst 122 (1997) 949.

[22] C.G. Bailey, S.R. Wallenborg, Electrophoresis 21 (2000) 3081.

[23] J.E. Melanson, C.A. Boulet, C.A. Lucy, Anal. Chem. 73 (2001) 1809.

[24] T.C. Chiu, M.F. Huang, C.C. Huang, M.M. Hsieh, H.T. Chang, Electrophoresis 23 (2002) 449.

[25] E.S. Yeung, W.G. Kuhr, Anal. Chem. 63 (1991) 275A.

[26] T. Soga, G.A. Ross, J. Chromatogr. A 837 (1999) 231.

[27] C. Johns, M. Macka, P.R. Haddad, Electrophoresis 21 (2000) 1312.

[28] P. Boček, P. Gebauer, J.L. Beckers, Electrophoresis 22 (2001) 1106.

[29] E. Dabek-Zlotorzynska, K. Keppel-Jones, LCGC 18 (2000) 950.

[30] M. Macka, C. Johns, P. Doble, P.R. Haddad, LCGC 19 (2001) 178.

[31] A.M. Desbène, C.J. Morin, N.L. Mofaddel, R.S. Groult, J. Chromatogr. A 716 (1995) 279.

[32] C.J. Morin, N.L. Mofaddel, A.M. Desbène, P.L. Desbène, J. Chromatogr. A 872 (2000) 247.

[33] S.Y. Chang, C.H. Liao, J. Chromatogr. A 959 (2002) 309. 
[34] P.L. Desbène, C.J. Morin, A.M. Desbène Monvernay, R.S. Groult, J. Chromatogr. A 689 (1995) 135.

[35] J.L. Beckers, J. Chromatogr. A 679 (1994) 153.

[36] L. Gross, E.S. Yeung, Anal. Chem. 62 (1990) 427.

[37] K. Bächmann, J. Boden, I. Haumann, J. Chromatogr. 626 (1992) 259.

[38] F.M.M. Morel, Principles of Aquatic Chemistry, Wiley/Interscience, USA, 1944 (Chapter 6).

[39] S.C. Wang, M.D. Morris, Anal. Chem. 72 (2000) 1448.
[40] S.L. Wang, X.J. Huang, Z.L. Fang, Anal. Chem. 73 (2001) 4545.

[41] S. Hillebrand, J.R. Schoffen, M. Mandaji, C. Termignoni, H.P.H. Grieneisen, T.B.L. Kist, Electrophoresis 23 (2002) 2445.

[42] A. Padarauskas, V. Olšauskaite, G. Schwedt, J. Chromatogr. A 800 (1998) 369.

[43] X.R. Wang, Z. Zhuang, D. Sun, J. Hong, X. Wu, F.S.C. Lee, M.S. Yang, H.W. Yeung, At. Spectrosc. 20 (1999) 86. 